\title{
ANALISIS EFEKTIFITAS CEFAZOLINE, CEFTRIAXONE, CEFOTAXIME SEBAGAI ANTIBIOTIK PROFILAKSIS PADA PASIEN SECTIO CAESAREA
}

\author{
Ninik Mas Ulfa, Selly Septi Fandinata, Yuni Hendrawati \\ Akademi Farmasi Surabaya \\ Email: ninik.mu@akfarsurabaya.ac.id
}

\begin{abstract}
Prophylactic antibiotics is very necessary in labor with the aim of avoiding infection during SC surgery. This study was descriptive observational with retrospective data collection. The subjects observed in this study were medical records documents of SC patients in RJI hospitals in the area of South Surabaya for the period February - April 2017, with 39 documents were divided into 3 groups. Group $A$ which received Cefazolin, Group $B$ received Ceftriaxone, and Group $C$ which received Ceftaxime. This study was comparison of the effectiveness of these 3 prophylactic antibiotics was measured by temperature parameters, leukocytes and observation of the condition of the surgical wound. Based on statistical analysis using the Kruskal Wallis test, it was found that the effectiveness of antibiotic prophylaxis Cefazolin was more effective in reducing the temperature and leukocytes of SC patients compared to Ceftriaxon and Cefotaxim, with an average rating of Cefazolin in temperature parameters of 27.58 and an average ranking in leukocyte parameters ie 25.81 . Meanwhile in observing surgical wounds from three groups of antibiotic prophylaxis there was no redness, no swollen wounds, no discharge and no pus from surgical wounds
\end{abstract}

Key words : Propylactic Antibiotic, Cefazoline, Ceftriaxone, Cefotaxime.

\section{PENDAHULUAN}

Sectio caesarea merupakan suatu proses persalinan buatan dimana janin dikeluarkan dengan cara insisi pada daerah antara dinding perut dan dinding rahim. Sectio caesarea (SC) merupakan jenis operasi bersih, tetapi beresiko infeksi pasca persalinan. Infeksi yang banyak terjadi adalah endometritis akut, dimana peluang kejadian 10 kali lebih besar dibanding persalinan normal. Terjadinya infeksi merupakan salah satu kontributor kematian ibu di Indonesia sebesar $15 \%{ }^{1}$ Antibiotika profilaksis merupakan salah satu cara untuk mencegah infeksi saat proses operasi bedah SC maupun pascah bedah SC. Pemberian antibiotik profilaksis pada SC terbukti efektif sebesar $89,18 \%$, tidak efektif sebesar $4,05 \%$ yang menunjukkan adanya kejadian infeksi. Efektivitas dari suatu antibiotik dapat dilihat dari jenis antibiotik, dosis, frekuensi dan lama perawatan pasien. ${ }^{2}$

Penggunaan antibiotik profilaksis golongan Sefalosporin banyak digunakan di setiap Rumah Sakit di Indonesia. Berdasarkan penelitian oleh Elsa, Welinda, Rolan tahun 2016 tentang Pola Penggunaan Antibiotik pada Pasien Bedah SC di Rumah Sakit Islam Samarinda memberikan hasil penelitian bahwa pemakaian antibiotik profilaksis tertinggi adalah golongan Sefalosporin yaitu Sefotaksim 73,5\% kemudian Seftriakson 0,66 $\%$ dan Amoksisilin 0,66 \% dan terbukti mencegah adanya infeksi luka operasi (ILO) 
Analisis efektifitas cefazoline, ceftriaxone, cefotaxime sebagai antibiotik profilaksis pada pasien Sectio caesarea.

pasca operasi. ${ }^{3}$ Sedangkan penelitian yang dilakukan oleh Nuraliyah, Hapsari dan Utaminingrum tahun 2012 tentang Evaluasi Penggunaan Antibiotik Pasien SC di Rumah Sakit Bedah daerah Purbalingga memberikan hasil penelitian bahwa antibiotik profilaksis terbanyak yang digunakan adalah golongan Sefalosporin $73,2 \%$, kemudian golongan Penicillin $24,05 \%{ }^{4}$

Berdasarkan latar belakang tersebut diatas, maka dilakukan analisis efektivitas dari antibiotik profilaksis golongan Sefalosporin yaitu Cefazoline, Ceftriaxone, dan Cefotaxime pada pasien bedah SC. Penelitian ini dilakukan di Rumah Sakit wilayah Surabaya Selatan yaitu Rumah Sakit RJI. Tujuan dari penelitian ini adalah untuk mengetahui efektifitas dari pemberian antibiotik profilaksis Cefazoline, Ceftriaxone dan Cefotaxime pada pasien SC dengan pengukuran pada 3 parameter yaitu suhu pre-post, leukosit prepost, dan pengamatan pada bekas luka operasi SC berupa bengkak, kemerahan, keluarnya cairan pada bekas luka dan push (nana).

\section{METODE PENELITIAN}

Penelitian bersifat diskriptif observasional dengan arah pengambilan data secara retrospektif. Data yang diambil pada penelitian ini diperoleh dari data rekam medik pasien SC di Rumah Sakit ROS dan Rumah Sakit RJI di wilayah Surabaya Selatan bulan Februari-April 2017. Populasi terjangkau pada penelitian ini adalah semua data rekam medis pasien SC yang mendapatkan antibiotik profilaksis Cefazoline, Ceftriaxone, Cefotaxime periode Februari - April 2017 di rumah sakit ROS dan RJI wilayah Surabaya Selatan.

Besar sampel pada penelitian ini adalah yang memenuhi kriteria inklusi, dan dihitung berdasarkan rumus Slovin sehingga diperoleh besar sampel total adalah 39 Pasien SC. Dari 39 pasien SC tersebut terbagi menjadi 3 kelompok dengan jumlah sampel masing-masing 13 pasien $(n=13)$. Kelompok terapi tersebut adalah kelompok $A$ yang mendapatkan antibiotik profilaksis Cefazoline intra vena (i.v) dosis 2 gram 30 menit sebelum operasi. Untuk kelompok B mendapatkan antibiotik profilaksis Ceftriaxone i.v dosis 2 gram 30 menit sebelum operasi. Sedangkan kelompok $\mathrm{C}$ mendapatkan antibiotik profilaksis Cefotaxime i.v dosis 2 gram 30 menit sebelum operasi. Pengukuran yang diamati pada 3 kelompok tersebut adalah mencatat nilai suhu pre-post operasi, mencatat leukosit pre-post operasi, dan mencatat kondisi luka pasca operasi dengan melihat tanda-tanda infeksi yaitu bengkak, kemerahan, keluarnya cairan pada bekas luka dan push (nana) pada 3 kelompok tersebut. Instrument yang digunakan pada penelitian ini adalah data rekam medis pasien.

Data yang diperoleh dianalisis secara diskriptif dalam bentuk prosentase tabel. Untuk data suhu pre-post, leukosit pre-post setelah operasi dari 3 kelompok tersebut, selain dianalisis secara diskriptif juga dilakukan analisis statistiK menggunakan uji Kolmogorov-Smirnov dan uji Kruskal Wallis.

\section{HASIL DAN PEMBAHASAN}

Berdasarkan hasil penelitian yang dilakukan oleh peneliti selama 2 bulan yaitu Januari sampai dengan Februari 2017 dari rekam medis pasien yang menjalani SC bulan Februari-April 2018 di Rumah Sakit RJI wilayah Surabaya selatan diperoleh sejumlah 39 pasien wanita, dengan kriteria usia pada tabel 1 dibawah ini. 
Analisis efektifitas cefazoline, ceftriaxone, cefotaxime sebagai antibiotik profilaksis pada pasien Sectio caesarea.

Tabel 1. Karakteristik pasien SC yang mendapat antibiotik profilaksis cefazoline, ceftriaxone, cefotaxime secara intra vena.

\begin{tabular}{ccccccc}
\hline \multirow{2}{*}{$\begin{array}{c}\text { Usia } \\
\text { (Tahun) }\end{array}$} & \multicolumn{2}{c}{$\begin{array}{c}\text { Cefazoline } \\
\text { (Kelompok A) }\end{array}$} & \multicolumn{2}{c}{$\begin{array}{c}\text { Ceftriaxone } \\
\text { (Kelompok B) }\end{array}$} & \multicolumn{2}{c}{$\begin{array}{c}\text { Cefotaxime } \\
\text { (Kelompok C) }\end{array}$} \\
\cline { 2 - 7 } & $\begin{array}{c}\text { Jumlah } \\
\text { pasien }\end{array}$ & $\begin{array}{c}\text { Persentase } \\
(\%)\end{array}$ & $\begin{array}{c}\text { Jumlah } \\
\text { Pasein }\end{array}$ & $\begin{array}{c}\text { Persentase } \\
(\%)\end{array}$ & $\begin{array}{c}\text { Jumlah } \\
\text { Pasien }\end{array}$ & $\begin{array}{c}\text { Persentase } \\
(\%)\end{array}$ \\
\hline $23-28$ & 7 & 54 & 3 & 23 & 6 & 46 \\
$29-34$ & 3 & 23 & 7 & 54 & 4 & 31 \\
$35-40$ & 3 & 23 & 3 & 23 & 3 & 23 \\
\hline TOTAL & $\mathbf{1 3}$ & $\mathbf{1 0 0}$ & $\mathbf{1 3}$ & $\mathbf{1 0 0}$ & $\mathbf{1 3}$ & $\mathbf{1 0 0}$ \\
\hline
\end{tabular}

Dari tabel diatas berdasarkan usia, diperoleh usia pasien terbanyak pada kelompok usia antara 23 - 28 tahun sebanyak 7 pasien (54\%) pada kelompok A yang mendapatkan antibiotik profilaksis Cefazoline i.v dan sebanyak 6 pasien (46\%) pada kelompok $\mathrm{C}$ yang mendapatkan antibiotik profilaksis Cefotaxime i.v. Sedangkan pada kelompok $B$ yang mendapatkan antibiotik profilaksis Ceftriaxone i.v terbanyak pada usia 29 - 34 tahun. Untuk kelompok usia terendah yang menjalani SC adalah kelompok usia 35 40 tahun. Berdasarkan hasil peneltian pada tabel 1 diatas menunjukkan bahwa organ reproduksi masih berfungsi dengan baik pada kelompok wanita usia produktif (23 tahun hingga 40 tahun) sehingga kelahiran bayi masih dapat terjadi pada rentang usia tersebut. Berikut adalah tabel hasil penelitian yang menunjukkan karakteristik faktor penyebab dilakukannya operasi SC.

Tabel 2. Karakteristik faktor penyebab SC

\begin{tabular}{lcccccc}
\hline \multirow{2}{*}{$\begin{array}{c}\text { Causing } \\
\text { Factors }\end{array}$} & \multicolumn{2}{c}{ Cefazolin } & \multicolumn{2}{c}{ Ceftriaxon } & \multicolumn{2}{c}{ Cefotaxim } \\
\cline { 2 - 7 } & $\begin{array}{c}\text { Jumlah } \\
\text { Pasien }\end{array}$ & $\begin{array}{c}\text { Persentase } \\
(\%)\end{array}$ & $\begin{array}{c}\text { Jumlah } \\
\text { Pasien }\end{array}$ & $\begin{array}{c}\text { Persentase } \\
(\%)\end{array}$ & $\begin{array}{c}\text { Jumlah } \\
\text { Pasien }\end{array}$ & $\begin{array}{c}\text { Persentase } \\
(\%)\end{array}$ \\
\hline $\begin{array}{l}\text { Oligohidramnion } \\
\text { Ketuban pecah }\end{array}$ & 2 & 15 & 3 & 23 & 2 & 15 \\
dini & 3 & 23 & 3 & 23 & 4 & 31 \\
$\begin{array}{l}\text { Bekas SC } \\
\text { Letak bayi }\end{array}$ & 4 & 31 & 4 & 31 & 4 & 31 \\
$\begin{array}{l}\text { sungsan } \\
\text { Kehamilan }\end{array}$ & 1 & 8 & 1 & 8 & 1 & 8 \\
ganda & 3 & 23 & 2 & 15 & 2 & 15 \\
\hline TOTAL & $\mathbf{1 3}$ & $\mathbf{1 0 0}$ & $\mathbf{1 3}$ & $\mathbf{1 0 0 \%}$ & $\mathbf{1 3}$ & $\mathbf{1 0 0 \%}$ \\
\hline
\end{tabular}

Berdasarkan tabel 2 diatas

menunjukkan hasil penelitian bahwa penyebab terbanyak dilakukannya operasi SC adalah adanya bekas SC pada 3 kelompok terapi tersebut, masing-masing 4 orang pasien (31 \%). Hal ini menunjukkan bahwa pasien wanita yang dalam proses partus pertamanya mengalami operasi SC maka pada proses partus selanjutnya kemungkinan juga akan mengalami partus secara SC, dikarenakan masih adanya bekas luka meskipun sudah membaik kondisinya pada operasi SC partus sebelumnya.

Berikut adalah tabel hasil penelitian yang menunjukkan pengukuran parameter suhu pre dan post pasien yang menjalani SC dari 3 kelompok terapi yang mendapatkan antibiotik profilaksis. Kelompok Terapi A 
Analisis efektifitas cefazoline, ceftriaxone, cefotaxime sebagai antibiotik profilaksis pada pasien Sectio caesarea.

mendapatkan antibiotik profilaksis Cefazoline,

yang mendapatkan antibiotik profilaksis

Kelompok Terapi B mendapatkan antibiotik

Cefotaxime.

profilaksis Ceftriaxone dan Kelompok Terapi B

Tabel 3. Profil suhu pre-post SC dari pemberian antibiotik profilaksis pada 3 kelompok terapi.

\begin{tabular}{|c|c|c|c|c|c|c|c|c|c|c|c|c|}
\hline \multirow{2}{*}{$\begin{array}{c}\text { No. } \\
\text { Pasien }\end{array}$} & \multicolumn{4}{|c|}{$\begin{array}{l}\text { Cefazoline } \\
\text { Suhu }\left({ }^{\circ} \mathrm{C}\right)\end{array}$} & \multicolumn{4}{|c|}{$\begin{array}{l}\text { Ceftriaxone } \\
\text { Suhu }\left({ }^{\circ} \mathrm{C}\right)\end{array}$} & \multicolumn{4}{|c|}{$\begin{array}{c}\text { Cefotaxime } \\
\text { Suhu }\left({ }^{\circ} \mathrm{C}\right)\end{array}$} \\
\hline & Pre & Post & $\Delta$ & $\%$ & Pre & Post & $\Delta$ & $\%$ & Pre & Post & $\Delta$ & $\%$ \\
\hline 1 & 36,5 & 36,0 & 0,5 & 1,37 & 36,7 & 36 & 0,7 & 1,91 & 36,7 & 36,3 & 0,4 & 1,09 \\
\hline 2 & 37,0 & 36,6 & 0,4 & 1,08 & 36,6 & 36 & 0,6 & 1,64 & 36,5 & 36,3 & 0,2 & 0,55 \\
\hline 3 & 36,3 & 36,2 & 0,1 & 0,28 & 36,5 & 36,2 & 0,3 & 0,82 & 36,7 & 36,4 & 0,3 & 0,82 \\
\hline 4 & 36,4 & 36,0 & 0,4 & 1,10 & 36,8 & 36,5 & 0,3 & 0,82 & 36,3 & 36,0 & 0,3 & 0,83 \\
\hline 5 & 37,5 & 36,5 & 1,0 & 2,67 & 36,5 & 35,8 & 0,7 & 1,92 & 36,8 & 36,5 & 0,3 & 0,82 \\
\hline 6 & 36,5 & 35,0 & 1,5 & 4,11 & 36,8 & 36,3 & 0,5 & 1,36 & 36,5 & 36,5 & 0 & 0,00 \\
\hline 7 & 36,8 & 36,3 & 0,5 & 1,36 & 36,7 & 36,0 & 0,7 & 1,91 & 36,7 & 36,4 & 0,3 & 0,82 \\
\hline 8 & 37,0 & 36,5 & 1,5 & 4,05 & 36,5 & 36,3 & 0,2 & 0,55 & 36,7 & 36,5 & 0,2 & 0,54 \\
\hline 9 & 36,3 & 35,6 & 0,7 & 1,93 & 36,8 & 36,4 & 0,4 & 1,09 & 36,5 & 36,0 & 0,5 & 1,37 \\
\hline 10 & 36,4 & 36,0 & 0,4 & 1,10 & 36,5 & 35,9 & 0,6 & 1,64 & 36,4 & 36,2 & 0,2 & 0,55 \\
\hline 11 & 37,3 & 36,5 & 0,8 & 2,14 & 36,4 & 36,3 & 0,1 & 0,27 & 36,5 & 36,4 & 0,1 & 0,27 \\
\hline 12 & 37,5 & 36,0 & 1,5 & 4,00 & 36,5 & 36,0 & 0,5 & 1,37 & 36,6 & 36,3 & 0,3 & 0,82 \\
\hline 13 & 36,4 & 35,5 & 0,9 & 2,47 & 36,6 & 35,9 & 0,7 & 1,91 & 36,7 & 36,6 & 0,1 & 0,27 \\
\hline TOTAL $\Delta$ & & & 10,2 & 27,7 & & & 6,3 & 17,2 & & & 3,2 & 8,7 \\
\hline Rata-rata & & & 0,8 & 2,1 & & & 0,5 & 1,3 & & & 0,3 & 0,7 \\
\hline
\end{tabular}

Berdasarkan tabel 3 diatas, menunjukkan bahwa kelompok terapi $\mathrm{A}$ yang mendapatkan antibiotik profilaksis Cefazoline dapat menurunkan suhu pasien yang menjalani SC sebesar 27,7\%. Sedangkan pada kelompok terapi B yang mendapatkan antibiotik profilaksis Ceftriaxone dapat menurunkan suhu pasien yang menjalani operasi SC sebesar $17,2 \%$ dan untuk kelompok terapi $\mathrm{C}$ yang mendapatkan antibiotik profilaksis Cefotaxime sebesar 8,7\%

. Berdasarkan tabel tersebut diatas, secara analisis diskriptif dengan membandingkan prosentase hasil dapat dikatakan bahwa antibiotik profilaksis Cefazoline lebih baik dalam menurunkan suhu pasien yang menjalani SC dalam artian menjaga agar suhu tubuh pasien tersebut tetap dalam batas normal yaitu antara $35^{\circ} \mathrm{C}-37^{\circ} \mathrm{C}$, sehingga setelah operasi SC pasien tidak mengalami peningkatan suhu diatas normal.

Berdasarkan analisis diskriptif tentang pengukuran suhu pre-post pasien sc diatas, dilanjutkan analisis statistik dengan menggunakan uji Normalitas dan uji Homogenitas data dari pengukuran $\Delta$ suhu SC. Tabel dibawah ini menunjukkan hasil uji Normalitas dan uji Homogenitas pengukuran suhu.

Tabel 4. Hasil uji normalitas dan uji homogenitas data $\Delta$ suhu pasien SC pada 3 kelompok terapi menggunakan uji Kolmogorov-Smirnov

\begin{tabular}{|c|c|c|c|}
\hline Parameter & Hasil Uji Normalitas & Hasil Uji Homogenitas & $\begin{array}{l}\text { Uji yang digunakan untuk } \\
\text { mengukur efektifitas antibiotik } \\
\text { profilaksis }\end{array}$ \\
\hline$\Delta$ Suhu & $\begin{array}{ll}\alpha=0,2, & \text { nilai } \alpha \geq 0,5 \\
\text { Datar } \quad \text { Berdistribusi } \\
\text { Normal }\end{array}$ & $\begin{array}{l}\alpha=0,000 \text { (Based Mean) and } \\
0,001 \text { (Based Median), nilai } \alpha \\
\leq \quad 0,05 \text { artinya data tidak } \\
\text { Homogen }\end{array}$ & Kruskal Wallis Test \\
\hline
\end{tabular}


Analisis efektifitas cefazoline, ceftriaxone, cefotaxime sebagai antibiotik profilaksis pada pasien Sectio caesarea.

Berdasarkan tabel 4 diatas, diperoleh hasil uji Normalitas data $\Delta$ suhu berditribusi normal menggunakan uji KolmogorovSmirnov. Sedangkan hasil uji homogenitas data $\Delta$ suhu menghasilkan data tidak homogen, sehingga dari kedua uji diatas dapat ditentukan analisis statistik menggunakan Uji Kruskal Wallis.
Tabel dibawah ini menunjukkan hasil analisis statistik parameter suhu pre-post pasien SC menggunakan Uji Kruskal Wallis. Uji ini digunakan untuk melihat efektifitas dari pemberian ketiga antibiotik profilaksis dalam 3 kelompok terapi.

Tabel 5. Hasil analisis statistik uji efektifitas antibiotik profilaksis pada kelompok terapi A (cefazoline), kelompok terapi B (ceftriaxone), kelompok terapi C (Cefotaxime) dengan parameter Suhu tubuh

\begin{tabular}{ccc}
\hline Parameter & Analisis Uji Efektifitas & Hasil Analisis Uji Efektifitas \\
\hline & & Mean Rank : \\
\multirow{2}{*}{ K Suhu } & Cruskal Wallis Test & Cefazoline $(N=13): 27,58$ \\
& & Cefotaxime $(N=13): 21,77$ \\
& & \\
\hline
\end{tabular}

Berdasarkan tabel 5 diatas, diperoleh hasil bahwa Cefazolin mempunyai nilai mean rank yang tinggi yaitu 27,58 dibandingkan dengan Ceftriaxone 21,77 dan Cefotaxime 10,65. Hal ini menunjukkan secara statistik bahwa Cefazoline mempunyai efektivitas yang lebih baik sebagai antibiotik profilaksis dalam pengontrolan suhu tubuh pasien SC, karena salah satu ciri adanya infeksi oleh bakteri adalah dengan adanya peningkatan suhu tubuh diatas normal setelah operasi tetapi hal ini tidak terjadi pada pasien SC yang mendapat antibiotik profilaksis Cefazoline pada penelitian ini. Selain parameter pengukuran suhu yang diamati dalam penelitian ini untuk penentuan efektivitas antibiotik profilaksis pada pasien SC, juga dilakukan pengamatan pada pengukuran parameter Leukosit dan kondisi bekas luka SC.

Tabel hasil penelitian dibawah ini menunjukkan pengukuran parameter Leukosit pre dan post pasien yang menjalani SC dari 3 kelompok terapi yang mendapatkan antibiotik profilaksis. Kelompok Terapi A mendapatkan antibiotik profilaksis Cefazoline, Kelompok Terapi B mendapatkan antibiotik profilaksis Ceftriaxone dan Kelompok Terapi B yang mendapatkan antibiotik profilaksis Cefotaxime.

Tabel 6. Profil leukosit pre-post SC dari pemberian antibiotik profilaksis pada kelompok terapi cefazoline

\begin{tabular}{ccccc}
\hline $\begin{array}{c}\text { No. } \\
\text { Pasien }\end{array}$ & $\begin{array}{c}\text { Leukosit pre } \\
\text { (/mmcell) }\end{array}$ & $\begin{array}{c}\text { Leukosit post } \\
\text { (/mmcell) }\end{array}$ & $\begin{array}{c}\Delta \text { Leukosit } \\
\text { (/mmcell) }\end{array}$ & \% Penurunan \\
\hline 1 & 13510 & 11420 & 2090 & 15,47 \\
2 & 12200 & 9900 & 2300 & 18,85 \\
3 & 10470 & 8980 & 1490 & 14,23 \\
4 & 10390 & 8810 & 1580 & 15,21 \\
5 & 10600 & 7570 & 3030 & 28,58 \\
6 & 9990 & 8440 & 1550 & 15,52 \\
7 & 13630 & 10530 & 3100 & 22,74 \\
8 & 10880 & 9360 & 1520 & 13,97
\end{tabular}


Analisis efektifitas cefazoline, ceftriaxone, cefotaxime sebagai antibiotik profilaksis pada pasien Sectio caesarea.

\begin{tabular}{ccccc}
9 & 13010 & 8800 & 4210 & 32,36 \\
10 & 7140 & 6200 & 940 & 13,17 \\
11 & 10190 & 7880 & 2310 & 22,67 \\
12 & 10850 & 7470 & 3380 & 31,15 \\
13 & 10520 & 7210 & 3310 & 31,46 \\
\hline TOTAL $\Delta$ & & & & 275,38 \\
\hline Rata-rata & & & & 21,18 \\
\hline
\end{tabular}

Tabel 7. Profil leukosit pre-post SC dari pemberian antibiotik profilaksis pada kelompok terapi ceftriaxone.

\begin{tabular}{ccccc}
\hline $\begin{array}{c}\text { No. } \\
\text { Pasien }\end{array}$ & $\begin{array}{c}\text { Leukosit pre } \\
\text { (/mmcell) }\end{array}$ & $\begin{array}{c}\text { Leukosit post } \\
\text { (/mmcell) }\end{array}$ & $\begin{array}{c}\Delta \text { Leukosit } \\
\text { (/mmcell) }\end{array}$ & \% Penurunan \\
\hline 1 & 9100 & 7100 & 2000 & 21,98 \\
2 & 8900 & 7100 & 1800 & 20,22 \\
3 & 8100 & 6900 & 1200 & 14,81 \\
4 & 12500 & 8100 & 4400 & 35,20 \\
5 & 10100 & 7900 & 2200 & 21,78 \\
6 & 10400 & 7300 & 3100 & 29,81 \\
7 & 9900 & 7100 & 2800 & 28,28 \\
8 & 9500 & 8800 & 700 & 7,37 \\
9 & 10400 & 7900 & 2500 & 24,04 \\
10 & 9500 & 8400 & 1100 & 11,58 \\
11 & 9900 & 8200 & 1700 & 17,17 \\
12 & 7800 & 6900 & 900 & 11,54 \\
13 & 9700 & 7200 & 2500 & 25,77 \\
\hline TOTAL $\Delta$ & & & 26900 & 269,56 \\
\hline Rata-rata & & & 2069,23 & 20,73 \\
\hline
\end{tabular}

Tabel 8. Profil leukosit pre-post SC dari pemberian antibiotik profilaksis pada kelompok terapi cefotaxime

\begin{tabular}{ccccc}
\hline $\begin{array}{c}\text { No. } \\
\text { Pasien }\end{array}$ & $\begin{array}{c}\text { Leukosit pre } \\
\text { (/mmcell) }\end{array}$ & $\begin{array}{c}\text { Leukosit post } \\
\text { (/mmcell) }\end{array}$ & $\begin{array}{c}\Delta \text { Leukosit } \\
\text { (/mmcell) }\end{array}$ & \% Penurunan \\
\hline 1 & 10000 & 8600 & 1400 & 14,00 \\
2 & 9900 & 8400 & 1500 & 15,15 \\
3 & 10400 & 9600 & 800 & 7,69 \\
4 & 8300 & 7000 & 1300 & 15,66 \\
5 & 9800 & 8100 & 1700 & 17,35 \\
6 & 9800 & 7900 & 1900 & 19,39 \\
7 & 10100 & 8900 & 1200 & 11,88 \\
8 & 8600 & 8000 & 600 & 6,98 \\
9 & 9200 & 8100 & 1100 & 11,96 \\
10 & 8600 & 7100 & 1500 & 17,44 \\
11 & 9600 & 9000 & 600 & 6,25 \\
12 & 10300 & 9100 & 1200 & 11,65 \\
13 & 11800 & 9800 & 2000 & 16,95 \\
\hline TOTAL $\Delta$ & & & 16800 & 172,35 \\
\hline Rata-rata & & & 1292,30 & 13,25 \\
\hline
\end{tabular}

Berdasarkan tabel 6, tabel 7 dan tabel 8 tentang profil leukosit pada pasien SC yang mendapatkan antibiotik profilaksis Cefazolin, Ceftriaxon dan Cefotaxim diperoleh hasil bahwa terjadi penurunan Leukosit pre - post pada pemberian antibiotik Cefazoline sebanyak 21,18 \% (terdapat penurunan 0,02118 kali dari Leukosit pre). Pada pemberian antibiotik Ceftriaxone diperoleh penurunan Leukosit pre-post sebanyak 20,73 $\%$ (terdapat penurunan 0,0273 kali dari Leukosit pre), sedangkan terdapat penurunan 
Analisis efektifitas cefazoline, ceftriaxone, cefotaxime sebagai antibiotik profilaksis pada pasien Sectio caesarea.

Leukosit pre-post sebanyak 13,25 \% (menurun 0,1325 kali dari Leukosit pre) untuk antibiotik profilaksis Cefotaxime. Hasil analisis secara dikriptif tersebut menunjukkan bahwa Cefazoline lebih baik dalam menurunkan jumlah Leukosit pasien setelah menjalani operasi SC, diperoleh hasil bahwa Cefazoline lebih baik menurunkan Leukosit sebanyak $21,18 \%$ dibandingkan dengan Ceftriaxone $20,73 \%$ dan Cefotaxime $13,25 \%$. Selanjutnya dilakukan analisis statistik untuk melihat distribusi data dan homogenitas data $\Delta$ Leukosit dari 3 kelompok terapi dengan menggunakan Kolmogorov-Smirnov. Hasil dapat dilihat pada tabel 9.

Berdasarkan tabel 9, diperoleh bahwa untuk data Leukosit bersiatribusi normal, tetapi data tidak homogen dengan menggunakan uji Kolmogorov-Smirnov, sehingga untuk efektivitas 3 antibiotik profilaksis tersebut yang terbagi dalam 3 kelompok terapi menggunakan uji Kruskal Wallis.

Tabel 10 adalah hasil uji efektivitas antibiotik profilaksis dengan menggunakan uji Kruskal Wallis.

Tabel 9. Hasil uji normalitas dan uji homogenitas data $\Delta$ Suhu pasien SC pada 3 kelompok terapi menggunakan uji Kolmogorov-Smirnov

\begin{tabular}{llll}
\hline Parameter & Hasil Uji Normalitas & Hasil Uji Homogenitas & $\begin{array}{c}\text { Uji yang digunakan untuk } \\
\text { mengukur efektifitas } \\
\text { antibiotik profilaksis }\end{array}$ \\
\hline \multirow{3}{*}{$\Delta$ Leukosit } & $\begin{array}{l}\alpha=0,036 \text { (Based Mean) } \\
\text { dan 0,049 (Based }\end{array}$ & \\
& $\begin{array}{l}\text { Data berdistribusi } \\
\text { Normal }\end{array}$ & $\begin{array}{l}\text { Median), hasil uji } \\
\text { menunjukkan } \alpha \leq 0.05 \\
\text { yang artinya data tidak } \\
\text { homogen }\end{array}$ & Kruskal Wallis Test \\
\hline
\end{tabular}

Tabel 10. Hasil analisis statistik uji efektifitas antibiotik profilaksis pada kelompok terapi A (cefazoline), kelompok terapi B (ceftriaxone), kelompok terapi C (cefotaxime) dengan parameter leukosit.

\begin{tabular}{lll}
\hline Parameter & Analisis Uji Efektifitas & $\begin{array}{c}\text { Hasil Analisis Uji efektifitas antibiotik } \\
\text { profilaksis }\end{array}$ \\
\hline & & Mean Rank $:$ \\
$\Delta$ Leukosit & Kruskal Wallis Test & Cefazolin $(\mathrm{N}=13): 25,81$ \\
& & Ceftriaxon $(\mathrm{N}=13): 22,00$ \\
& Cefotaxim $(\mathrm{N}=13): 12,19$ \\
\hline
\end{tabular}

Berdasarkan tabel 10 diatas dari parameter $\Delta$ Leukosit menunjukkan nilai mean rank kelompok Cefazoline lebih besar yaitu 25,81 dari pada nilai mean rank keompok Ceftriaxone 22,00 dan kelompok Cefotaxime 12,19. Berdasarkan data tersebut menunjukkan bahwa Cefazoline dalam menurunkan leukosit pre-post $\mathrm{t}$ pasien SC lebih baik atau lebih efektiv dibandingkan dengan Ceftriakson maupun Cefotaxim.
Sehingga dari hasil penelitian ini dapat dikatakan bahwa Cefazoline mempunyai efektivitas yang baik sebagai antibiotik profilaksis dalam menurunkan suhu tubuh dan Leukosit pasien yang telah menjalani operasi SC sehingga dapat mencegah terjadi infeksi pasca operasi SC.

Pada penelitian ini selain menganalisis suhu tubuh pre-post dan leukosit pre-post pasien operasi SC, juga mengamati 
Analisis efektifitas cefazoline, ceftriaxone, cefotaxime sebagai antibiotik profilaksis pada pasien Sectio caesarea.

dengan cara mencatat hasil pada rekam

medis pasien berupa kondisi luka pasca

operasi yang dapat menunjukkan ada atau tidaknya luka infeksi. Tabel 11 dibawah ini merupakan hasil yang diperoleh dalam pengamatan kondisi luka setelah operasi SC.

Tabel 11. Kondisi luka paska operasi SC pada 3 kelompok terapi yang mendapatkan antibiotik profilaksis cefazoline, ceftriaxone, cefotaxime.

\begin{tabular}{lcccc}
\hline \multicolumn{1}{c}{ Kelompok Terapi } & Bengkak & Kemerahan & $\begin{array}{c}\text { Keluarnya Cairan } \\
\text { pada bekas luka }\end{array}$ & Push (Nana) \\
\hline Cefazolin $(n=13)$ & - & - & - & - \\
Ceftriaxon $(n=13)$ & - & - & - & - \\
Cefotaxim $(n=13)$ & - & - & - & - \\
\hline
\end{tabular}

Dari tabel 11 menunjukkan hasil bahwa tidak ditemukan adanya infeksi luka operasi paska SC. Hal ini menunjukkan bahwa dari ketiga Antibiotik profilaksis tersebut yang diberikan pada 3 kelompok terapi memberikan hasil bahwa ketiga antibiotik profilaksis tersebut efektif dalam menghambat adanya infeksi luka operasi pasca SC, karena dari total pasien sebanyak 39 orang tidak ada satu pun luka operasi yang membengkak, tidak kemerahan, tidak mengeluarkan cairan dan tidak mengeluarkan nanah (pus), yang menunjukkan bahwa pemberian antibiotik profilaksis efektif dalam menghambat terjadinya infeksi luka operasi. Hasil penelitian ini sama dengan penelitian yang dilakukan oleh oleh Yulia, Herawati, Jaelani, Anggraeni pada evaluasi penggunaan antibiotik profilaksis di RSUD Kabupaten Pasuruan tahun 2018 bahwa tidak ditemukan infeksi luka operasi pada pemakaian antibiotik Cefotaxime, Ceftriaxone, Cefazoline dan Ampisilin Sulbaktam. ${ }^{5}$

Berdasarkan hasil penelitian dari parameter pengukuran suhu, leukosit dan infeksi luka operasi pasca SC menunjukkan bahwa antibiotik Cefazoline lebih efektif sebagai antibiotik profilaksis dalam menghambat peningkatan leukosit dan peningkatan suhu, serta mencegah terjadinya infeksi luka operasi pasca SC. Untuk antibiotik Ceftriaxone dan Cefotaxime juga mempunyai efektifitas sebagai antibiotik profilaksis dalam mencegah infeksi setelah operasi tetapi tidak sekuat Cefazoline. Hal ini dikarenakan mekanisme kerja dari Cefazoline sebagai antibiotik Cefalosporin generasi pertama yang narrow spectrum yaitu hanya aktif pada bakteri gram positif. Cefazoline lebih aktif terhadap bakteri staphylococcus dan mempunyai spektruk bakteri yang lebih spesifik pada kasus bedah serta tidak menimbulkan resistensi sebagai antibiotik profilaksis. ${ }^{6}$ Bakteri gram positif ini sering terdapat pada bekas luka operasi bedah SC dibandingkan dengan Ceftriaxon dan Cefotaxim yang mempunyai aktivitas Broad spectrum dan sedikit aktif pada bakteri gram negatif. Hal ini juga sesuai dengan Pedoman Penggunaan Umum Antibiotik Permenkes tahun 2011 yang menyebutkan bahwa untuk operasi bedah sesar antibiotik profilaksis yang direkomendasikan adalah Cefalosporin generasi I (Cefazoline) dan II (Cefuroxime) ${ }^{7}$

\section{KESIMPULAN}

Berdasarkan hasil penelitian dapat disimpulkan bahwa Antibiotik profilaksis Cefazoline lebih efektif dalam menghambat terjadinya infeksi paska operasi SC berdasarkan pengukuran suhu tubuh pre-post 
Analisis efektifitas cefazoline, ceftriaxone, cefotaxime sebagai antibiotik profilaksis pada pasien Sectio caesarea.

dan leukosit pre-post pasien yang menjalani

SC, serta dapat menghambat terjadinya infeksi luka pasca operasi SC dengan tidak adanya bengkak, tidak adanya kemerahan, tidak ada keluarnya cairan bekas luka dan tidak ada push (nana). Diharapkan dari hasil penelitian ini dapat memberikan kontribusi bagi penggunaan antibiotik profilaksis pada operasi SC, dan pemberian antibiotik profilaksis yang terpilih adalah Cefazoline secara intra vena dengan dosis 2 gram yang diberikan 30 menit sebelum operasi sectio caesarea.

\section{DAFTAR PUSTAKA}

1. Prawirohardjo S. IImu Bedah Kebidanan. Jakarta : Yayasan Bina Pustaka Sarwono Prawirohardjo., 2009:133

2. Prasetya DB. Efektivitas Penggunaan Antibiotik Pada Pasien Seksio Sesarea Elektif Di Rumah Sakit X Sidoarjo. Jurnal IImiah Mahasiswa Universitas Surabaya. 2013; 2(2):1-10
3. Elsa, Welinda, Rolan. Pola Penggunaan Antibiotik pada Pasien Bedah SC di Rumah Sakit Islam Samarinda. Prosiding Seminar Nasional Kefarmasian Ke-3 Fakultas Farmasi Universitas Mulawarman. 2016. ISBN 978 - 602-73052-4-3 ; 22 - 28. https: //www.researchgate.net/publication/309923 223

4. Nuraliyah, Hapsari, Utaminingrum. Evaluasi Penggunaan Antibiotik Pasien SC di Rumah Sakit Bedah daerah Purbalingga. Jurnal Pharmacy. 2012 ; 9 (02): 31 - 39. ISSN 1693 - 3591

5. Rika $Y$, Herawati $F$, Jaelani A, Anggraini W. Evaluasi Penggunaan Antibiotik dan Profil Kuman Pada Seksio Sesarea di Rumah Sakit Umum Daerah Kabupaten Pasuruan. Jurnal Farmasi Klinik Indonesia. 2018; 7(2) : 69 - 77. ISSN 2252 - 6218

6. Katzung BG. Farmakologi Dasar dan Klinik, ed. 10. Jakarta: EGC., 2012 : 756-857.

7. Kementerian Kesehatan Republik Indonesia. Peraturan Menteri Kesehatan Republik Indonesia Nomor 2406/MENKES/PER/XII/2011. Pedoman Penggunaan Antibiotik, 2011. 